\title{
A Sociolinguistic Comparison Between Algerian and Maltese
}

\author{
Nassima Kerras, PhD \\ Moulay-Lahssan Baya E., PhD \\ Group HUM-835 “Translation, Knowledge and Culture” \\ - University of Granada, Spain
}

doi: 10.19044/esj.2016.v13n2p36 URL:http://dx.doi.org/10.19044/esj.2016.v13n2p36

\begin{abstract}
A sociolinguistic study is made of the Maltese language to compare it to the Algerian language. Algerian is not the official language in Algeria, although it is the national one, and in this article an empirical study is undertaken to question the particularities of Algerian and its formation, comparing it with Maltese which has itself gained official status.

Maltese, or "the language of the kitchen" as it is known, has gained important status on the island after decades of foreign occupation and linguistic influence from various civilizations that left palpable paw prints on the Mediterranean island. Maltese has managed to successfully confirm its linguistic identity, through a noticeable influence of Arabic, Italian and English amongst other languages that have imposed themselves and had a hand in forming the Maltese language.

A sociolinguistic and historical study is made to explain the formation of Algerian comparing it to Maltese and the influence of history in both languages.

A historical study is made to compare and observe the historic diachronic of both countries, and we compare the influence of foreign languages in Algeria and Malta. Likewise, an empirical study is undertaken to question the use of Algerian from various angles, and to examine the linguistic identity in Algeria.
\end{abstract}

Keywords: Algerian Identity, Algerian Language, Maltese Language, Sociolinguistic Study

\section{A historical study}

What follows is a brief historical study of Algeria and Malta, done in order to understand the cultural and linguistic influence in both countries. Although the entire history of both nations will not be mentioned here, for 
our purposes a brief review is made to understand civilizations that have been in the two states and that have played a role in their linguistic and cultural formation.

\section{Algeria}

Algeria is a country from the Mediterranean that has been occupied by various civilizations and nations. The Berbers were the first to occupy the zone for the last ten thousand years. Then, the region became occupied by Phoenicians (Carthaginians). In the third century, the Romans conquered the region, and in the year 430 Vandals took over, followed by the Abbassides, Fatimies, amongst other ethnical minorities, as commented by Benrabah (1999) by analysing Algerian's linguistic identity.

After the fall of Rome and the instability in the region between the Vandals and the Byzantines, the Umayyad people occupied the place from the year 670 until the year 708. In the sixth century, the Byzantines, which were later invaded by the Arabs in the eighth century. After the Muslim conquest, the citizens of the area adopted the local religion, and the language was also picked up little by little, a topic which has been mentioned by the author Benrabah (1999) from a political and linguistic point of view when he talks about linguistic traumatism in Algeria.

Before the year 1501 the Portuguese tried to conquer Algeria, and from this year onwards Algeria was left in the hands of the Spanish until 1792, when a commercial and peace treaty was signed.

From the year 1830, France progressively established an important colony until the independence of the country in 1962.

We will later observe the influence from the above-mentioned civilizations in the formation of Algerian linguistically, but now Malta will be reviewed historically to be able to compare the trajectory of both countries.

\section{Malta}

The inhabitants of the Mediterranean country Malta originate from Sicily. In the year 1000 A.C. the Phoenicians came, followed by the Greeks, then the Romans in the year 218 A.C.; the Byzantines in the year 533 and then Vandals occupied the land.

In the year 870 a grand-scale occupation by the Arabs took place, and this influence can still be felt to this day. In the year 1090 Arabs were substituted by the Normans from Sicily until 1282 when the throne was given to the Aragon people. In 1798 the region was conquered by the French in 1800 .

In 1814 Malta formally became part of the British Empire through the Paris Treaty, until its Independence in 1964. 
In the following unit, we study both countries from a sociolinguistic point of view in order to analyse linguistic particularities.

\section{A sociolinguistic study of the Maltese and Algerian languages}

After having looked back at the two countries' respective histories, it is now time to analyse the influence and the formation of the languages in each nation from a sociolinguistic point of view.

The Maltese language has been around and spoken for many years by its native people, the language called “The language of the kitchen" bares fruit from a long historic background, and is influenced by various civilizations as Sciriha (2002, p. 96) explains:

Malta's chequered history has included among its many colonisers, the Arabs (870-1090), the Normans (1090-1266); the Angevins (1266-1283); the Aragonese (1283-1410); the Castilians (1412-1530; the Order of St. John (1530-1798); the French (1798-1800) and the British (1800-1964). Malta obtained its independence in 1964 and Maltese, the indigenous language of the islanders, together with English, became the two official language of the country.

Malta is a bridge between Europe and North Africa and this situation is completely reflected in the Maltese culture and language, as expressed by Hoberman \& Aronoff (2003, p. 64):

Maltese is historically and genetically an Arabic dialect. Malta was under Muslim rule from 870 to 1090 and the population remained substantially Muslim until about 1250. Since about 1300, however, there has been very little contact with the Arab world, and Romancespeaking Europe has been the dominant political and cultural force in Malta; as a result, for instance, the Maltese people are Roman Catholics, and write their language with a version of the Roman alphabet. For these and similar reasons a sociolinguist might argue that Maltese has by now lost its status as a variety of Arabic, but we are talking about its origins and its structure, which remains very much within the Arabic type. It is striking and somewhat puzzling that a little over two hundred years of Muslim rule was sufficient to replace whatever language or languages had previously been spoken in Malta with Arabic, while the last seven hundred years have not seen that language supplants by Sicilian or Italian.

This situation is simultaneous to that of Algeria, as Algeria has been occupied in the past by many different civilizations and that can be seen in the spoken language. Guella (2011) did a lexical study which touches on the origin of various terms that come from the civilizations that influenced Algeria, for example, Guella mentions borrowings from the Berber language: fəkrūn [tortoise], atrūs [goat], gərzūma [throat], zərmūmiya [lizard], fərţəţəu 
[butterfly], azəllīf [lamb's head], qarqra [toad], shlāġəm [moustache], fallūs [chick]). Borrowings from the Turkic language: ţabşi [dish], tqāšīir [socks], bašmāq [slipper], bālāk [maybe], bāla [shovel], branīya [aubergine], zerda [feast]). Borrowings from the Spanish language: bəlg̀a [slippers], fâlta [fault], farīna [flour], batāta [potatos], swīrti [luck], šìta [brush], spardīna [sneakers], bugādu [lawyer], mizirīya [misery], kubīrta [blanket], ect.). Next, borrowings from French: tifīs [typhus], zūfri [worker], kazīrna [barrack], midāya [medal], bagīta [baguette], tipāna [bread], rubīni [tap], tīki [tiket]), among others terms and structures. A method of transliteration has been used that consists in using a specific computer keyboard, because Maltese is a mixed language between Semitic and Creole.

Concerning the phonetic transliteration of Arabic letters (mainly the consonants and long vowels) which have no equivalent in English (European) script, a system has been represented closely by means of the International Phonetic Alphabet. The system has been adopted for studies combining Arabic/English linguistics: ' $-\mathrm{b}-\mathrm{t}-\mathrm{th}-\mathrm{j}-\mathrm{h}-\mathrm{kh}-\mathrm{d}-\mathrm{dh}-\mathrm{r}-\mathrm{z}-\mathrm{s}$ - sh - s $-\mathrm{d}-\mathrm{t}-\mathrm{z}-{ }^{\prime}-\mathrm{gh}-\mathrm{f}-\mathrm{q}-\mathrm{k}-\mathrm{l}-\mathrm{m}-\mathrm{n}-\mathrm{h}-\mathrm{w}-\mathrm{y}$. The vowels: $\mathrm{a}-\mathrm{i}-\mathrm{u}$ - $\overline{\mathrm{a}}-\overline{\mathrm{i}}-\overline{\mathrm{u}}$; the diphthongs: ay - aw; and the "alif maqșūra" is á.

This situation has created a language which is complicated to analyse and to codify, while on the other hand Maltese was codified using the Roman alphabet through strong influence from Italian and English and because of the geographical situation of the country. This is explained by Sciriha (2002, p. 97):

Although Maltese was spoken by the islanders, during Vassalli's time the indigenous language was regarded as a non-standard language which was perceived to be of an inferior status to the other languages, especially Italian that were spoken in Malta. Until the 1920s the Maltese alphabet was not yet standardised and only in 1943 did Maltese supplant Italian to become the language of the administration together with English. Finally, in 1964, Malta became an Independent state and the Maltese constitution decreed English and Maltese to be the official languages, with Maltese also being the national language and the language of the courts.

Algerian has not yet been codified as a language for multiple reasons: the lack of research, the lack of consent, and a very pronounced political and spiritual influence. The language has not been codified due to the influence of French, which is extremely present in Algeria, which is also hard to ignore; and due to the Arabisation, which was established after the country's independence, due to the vital role Algeria plays in the Arab world. This problem has been studied by (Larzul, 2010, p.93), and he estimates that it is difficult to radically break with standard Arabic, which creates a gap within the normalization process of the Algerian language. Medane (2014, p. 1669- 
1671) clearly explains that a complexity and a diversity exists within Algerian linguistics, and despite the Arabisation politics established after the country's independence, French plays an important role in Algerian society, even if the actions brought about by Arabisation have been very present.

The hypotheses that are made in this study are as follows:

Which is the decisive factor for codifying the Algerian language? And; how could the Algerian language gain official status?

To answer these questions, we compare the creation of the Algerian language to that of the Maltese language as a model for the common points that each of the two countries share. Firstly, both countries are from the Mediterranean, situated in a crossroad, this means that these countries were conquered by almost the same civilizations that have influenced the formation of their national languages (see Table 1):

Table 1

\begin{tabular}{|c|c|}
\hline Algeria & Malta \\
\hline The Berbers & The Sicilians \\
The Phoenicians (Carthage) & The Phoenicians (Carthage) \\
The Greeks & The Greeks \\
The Romans & The Romans \\
The Byzantines & The Byzantines \\
The Vandals & The Vandals \\
The Abbasids & \\
The Fatimid & \\
The Umayyad & \\
The Arabs & The Arabs \\
The Portuguese & The Normans \\
The Spanish & The Aragonites \\
The French & The French \\
& The British \\
\hline
\end{tabular}

The Maltese language was formed by other languages, in the same way as Algerian, through historic factors. Pascale (2011, p. 528) explains the sociolinguistic situation of Maltese as follows: "Today, about half of the Maltese vocabulary comes from Italian and Sicilian words, with debatably as high as twenty percent from French and English (more from the latter), while roughly a third comes the Semitic Siculo-Arabic base”.

This is what happens with Algerian: a large percentage of its vocabulary comes from French, another large percentage originates from Arabic, a notable presence from Berber, then a lower amount of influence from Spanish and Turkish mainly. As explained by Benrabah (1999, p. 9): language is the medium of communication, a profound personal part of an individual and a collective, and it is the link between the past and the present, the contact which the individual has with its society, the relationship between the conscious and the unconscious, and the structure of personality. 
After the French war an Arabisation politics has come about that has not worked properly, due to the strong presence of the French language mainly, and by other linguistic presences such as Berber, Turkish or Spanish. The failure of Arab teaching in the system has been talked about by various linguists, and amongst there are Boubakour (2008, p. 61).

Maltese was mainly talked by its native people, but Italian and English were languages that were important also and used in the most part by intellectuals, as explained by Sciriha (2002, p. 104):

Maltese was only spoken by the illiterates, while educated Maltese preferred to interact in Italian. Since then political and cultural developments have given Maltese added value, and, especially after Independence in 1964, Maltese has come to be perceived an as essential component of national identity. This is clearly especially attested to in the flourishing literature in Maltese, in the diffusion of the language through both printed and live media, and the pervasive use of it by all strata in society as their standard medium for communication, even if at times used jointly with considerable codeswitching with English.

This is exactly what happens in Algerian society as Algerian was a dialect, or better explained, the language used by any Algerian, while educated French was used by intellectuals, but Algerian has acquired an important status in the last few years, as every single Algerian wants to impose their cultural and linguistic identity. Boubakour (2008, p. 54) states that Algerian is the language used by the majority of the Algerian people from a sociolinguistic point of view, and explains that it is a language whose vocabulary, or at least part of its language and its grammatical structures, come from the French language, although he uses as a denomination "L'arabe algérien" [the Algerian Arabic]. For our use we name it "Algerian language" because its etymology and grammatical structures derive from various languages, amongst these Arabic, but it is not the only language that is present here. Merzouk (2014, p. 104) insists that there is a diverse linguistic presence which is varied when talking about borrowing from the Berber language, which is part of Algerian's heritage and opens a rich linguistic umbrella.

Therefore, the Maltese language went from being known as "the language of the kitchen" to being the official language of Malta, due to it being the identity of the people, and the native language of the Maltese people, despite the importance of English. English is still the administrative language, but it is used in a bilingual fashion and is written in both versions. Regarding Codeswitching and Codemixing, it has become an official language due to this necessity to express one's identity, as told by Sciriha (2002, p. 105): "Both English and Maltese are equally important, the results 
evidence a see-saw that linguistic pattern as regards Malta's two official languages”. The English language has not stopped being an important language in Malta due to globalization and by the footprints left by colonizers, but the national language is recognized equally due to the importance of sealing the identity of each town. This is how Sciriha (2002, p. 105) expresses this sentiment:

Maltese documented by this study shows the status of this indigenous language has rocketed from rock, bottom position during the time when it was dubbed 'the language of the kitchen' to the top place it now holds. Participants in this study clearly perceive Maltese to be the most important language for a Maltese living in Malta today.

This is what happens with Algerian as it is clear that Algerian is important, in the same way that French is important, but it is necessary to recognize the Algerian language as part of Algeria's national identity. Camilleri (2016, p. 2) recognizes the importance of borrowings and influences from other languages in its linguistic formation: "While this is true that the Maltese language has been influenced by English on a number of linguistic levels such as the morphological and lexical ones".

The Algerian language is a language that originates from standard Arabic and French through its own structures and a lexicon in agreement with Algerian's linguistic conventions, as explained through some examples in the following chapter. Algerian is a type of codeswitching which is not intentional, it gets transmitted from one language to the other without thinking, and it is the native language of the average Algerian person, in the same way a Maltese person. Algerian has been borrowing words from other languages throughout history and from civilizations that passed through the north African lands, as clarified by Guella (2011, p. 81) who did a study about lexical borrowings from Algerian, and confirms that lexicons come from languages such as Berber, Turkish, Spanish, Italian and French. They are words that form part of the repertoire and its identity.

Next, an empirical and analytical study is performed to be able to observe the formation of the phonology, morphology and lexicon from Maltese, comparing it to Algerian.

\section{An empirical study of the Maltese and Algerian languages}

A study is made based on the linguistic corpus, with the objective of studying language through real examples to analyse Algerian's linguistic characteristics. Corpus linguistics is an empirical method that consists of obtaining knowledge about the languages you wish to understand better, through observation of a handful of specifically selected examples to be able to finally reach a general theory. This is based on experimentation and logic 
alongside observation and statistical analysis. The empirical method is deduced through the observation of the relationships between objects; you firstly identify the investigational problem, then formulate a hypothesis, gather the information (in our case, a certain amount of lexicon is gathered), and you work with this in order to reach a semantic, etymologic, phonetic and pragmatic point of view, to finally have the tools to either confirm or deny the hypothesis.

Firstly, the lexicon of a beginner's dictionary, Maltese learner's book, is analysed to study the etymology of Maltese, and to compare it with its equivalent in Algerian, emphasizing the phonetic values of both languages and the sociolinguistic factors.

The practical side has been divided into two parts: one will focus on phonetic aspects while the other on etymological and semantic aspects. In the first part, we tackle Maltese phonetics in the language's Lexus, a comparison with the equivalent in Algerian and standard Arabic has also been done, along with examples from both case-study languages and any pertinent comments. The second part focuses on studying the etymology of various Maltese terms, while also offering a thorough analysis of the proposed words in Algerian and standard Arabic.

Some examples have been taken from a Maltese learner's book as corpus in order to compare the formation of the language compared to Algerian.

\section{Phonetic study}

The first corpus of the book speaks of a human body-based vocabulary whose title is the following: "Il - Gisem Taghna” [our body]. All the sentence is of Arabic origin which was adapted to Maltese phonetics and alphabet. The structure is the same in Algerian "El - Gisem Taghna" or "El Corps Taghna" for the more Francophones people, however the phonetics in the article is different: "Il" for the Maltese and "El" for the Algerians, but the structure is the same between both languages although in Algeria the language is not codified and it can be written in Arabic or Latin writing. Arabic has been adapted to the Maltese linguistic system, which is different to standard Arabic "جسمنا”.

We see here how many words come from Arabic but these have been adapted the phonetic structure of each language. For the Maltese they are Maltese words, but for Algerians they are yet to be recognized as such: "Snien" in Maltese [teeth] whose equivalent in Algerian is "Sanien" of Arabic origin, but the phonetics is different to that of the standard Arabic language “أسنان". The word "Widna” in Maltese [ears] find its equivalent in the Algerian "Wednin", the phonetics is different comparing it to standard Arabic "أذن". The combination of the words "Saba" 1-kbir" [thumb] that is 
expressed in the same way in Maltese and in Algerian, whose phonetics in standard Arabic completely changes “"الأصبع الكبير”. The Maltese word "Dwiefer" [nail] is expressed according to linguistic conventions of each language: "Zfour" in Algerian, when its origin is Arabic and its phonetics is different “ظفر". The Maltese word “Sider” [chest], its phonetics are different in Algerian "Șdar" and in standard Arabic "صدر" although the origin of the word is the same.

We can also observe vocabulary related to family: The Maltese word "Familja" that originates from Latin, is expressed in the same way in Algeria "Familia”, while in standard Arabic it is "عائلة". The word [twins] is “Tewmin” in Maltese, “Twam” in Algerian and “تو أح "Th in standard Arabic and the phonetics is different although the root remains the same. The word [Woman] is expressed with the noun "Mara" in Maltese, [Mra] in Algerian and "إمرأة" in standard Arabic although the etymology is the same, each language has adapted depending of its social, biological and linguistic conventions, as explained by Hoberman \& Aronoff (2003, p. 65): “Maltese phonology has undergone many changes from the Classical Arabic pattern, but is still recognizably vernacular Arabic”.

As Martinet (1980, p. 42) explains: we can have an infinity of sounds between vowels, depending on the transmitter and articulatory modalities. We can find medium vowels, neutral vowels, centralized vowels, tense or loose vowels, nasal vowels, and the duration of the vowel sound can be long or short; we see as an example the following words which are pronounced almost in the same way but the phonetics of the $(E)$ is what creates the phonetic difference, the (E) in the word (maître) [master] is longer that the word (mettre) [to put] which is shorter. This depends on the position of the lips, the extent to which the mouth is open and the oval cavity. We give as an example an Algerian word "Belkhof" [quickly] which is pronounced differently between Algerian and Moroccan "Belkheffa" although they are very similar languages from a sociolinguistic and geographic point of view, while the noun in standard Arabic is different (بسر عة).

Larzul (2010, p. 93) studies Algerian’s grammar and estimates that it is difficult to radically break with literal Arabic including if vocalic colorations are different. For example: in Algerian, you can differentiate between the vowel (E), $(\mathrm{O})$ and (EU) easily due to the presence of the French language, while the Arabic language does not dispose of that many vowels.

\section{Etymologic and Semantic study}

In the vocabulary topic of clothes, some particularities have been observed in the same way: some words originate from Arabic and others are borrowed from other languages, for example, the Maltese word "lbies" [clothes] has "labsa" in Algerian which means the same, which comes from 
standard Arabic but the phonetics are totally different “"الألبسة". While Maltese uses "Kowt” to say "coat”, Algerian uses "Manteau” and never "معطف" which is the Arabic word. Maltese has borrowed the English word "Coat”, but it is transcribed following Maltese phonetic rules, while Algerian would pronounce it how you would pronounce it in French, although sometimes with an Algerian accent adding the Algerian definite article "El".

Maltese uses the combination of words "Dressing gown” is a correct use of English in the same way Algeria uses the equivalent in correct use of French "Robe de chambre" and it does not resort to Arabic. Both countries use the same word to designate pyjamas, the Maltese uses the words "Pigáma” and the Algerian "Pyjāma" which are words of Latin origin and in Algeria you never use the equivalent in Arabic "منامة" although the official language of the country is standard Arabic. The same happens with the noun "Cardigan" which is "Kardigan” in Maltese, a borrowing from English but which follows Maltese phonetics, the same happens with Algerian "Gardigan”, a word which is borrowed from French and its Arab counterpart is never used "سترة من صوف".

In another corpus called “Aktar hwejjeg li nilbsu” [Other clothes we put on] it is expressed in the same way than in Algerian "Akthar hwāyej li nālbsuhom”, the word “Akthar" comes from the Arabic “'أكثر”, while "ḥwāyej" is a word that is used only in North Africa, the relative "li" originates from Arabic “الذي" but it is adapted to the Algerian and Maltese phonetics, and the verb [put on] is adapted to the phonetics of the two countries, as in Standard Arabic the phonetics are different "نلبسهر".

The Maltese word is used "ngravata" [tie], when in Algerian it is "Cravata”, both languages have borrowed from Latin languages and they have adapted them to the linguistic conventions of each language, while in Arabic it is completely different " would never use in Algerian. The word "Buttuni" is used to refer to "buttons", when in Algerian you use "Boutons", borrowed from the French language, and you would never use the Arabic “'اردار" which is the official language of Algeria. The word "hendbeg” [handbag] borrowed from English and adapted to Maltese phonetics, and its equivalent in Algerian "Sac" borrowed from French and that on occasion has the Algerian definite article added to it "El sac", but this is never expressed in standard Arabic "الحقيبة".

Within the corpus of kitchen, we can also see some interesting word choices for nouns: "sikkina" is used in Maltese to refer to "knife", in Algerian the word "Khodmi" is used and in some areas "Sekin" of Arabic origin “سكين". Maltese uses “Furketta” to refer to “fork”, borrowed from English or Italian, in the same way as in Algerian the word "Farcheta" is used, which has its origin from Italian, but no one uses the Arabic version of “"شوكة". The Maltese word "Mgharfa” is used to designate "spoon” in the 
same way as the Algerian "Mgharfa" o "Moghrof” when in standard Arabic it is "ملعقة". The Maltese "Table mat" is used to designate the mat on the table, and Algerian uses “Set de table” and never “فرش الطبق". Although all Arabic words are taught in primary school until the end of secondary school to Algerians, reality shows that Algerian is actually the language that is used in Algeria, even if many words come from standard Arabic. It is the language that is used at home, at school, and even if you are taught in standard Arabic, communication between friends and colleagues is done in Algerian, the first language you learn as a child.

While the high socioeconomic class tends to teach French to its children, the importance of your mother tongue is clear, as it is the first language for communication and its use is generalized within the Algerian community. The importance of Algerian can be noticed in equal measure within immigrant communities in any country, the child usually tends to learn the language from the country they are residing in and also the language their parents are using. Standard Arabic is a foreign language for immigrants that have not picked up the initiative to study it in an academy, for example. As explained by Benrabah (1999): standard Arabic is not the structural identity point to follow as it is different from its users, while the variety of the languages which are spoken by most Algerians is the Algerian identity.

Although the standard Arabic language is the official language, its place in Algerian society is reduced, as properly explained by Merzouk (2014, p. 101): The French language and the Algerian language are very present in various scopes (banks, post offices, telecommunications, family environment, etc.) which in turn minimizes the role played by standard Arabic in Algeria. Algerian is a language that is used in much of media (radio, TV, internet, etc.) although it co-exists alongside French and Arabic (especially when it comes to the written form). The Algerian language is rich and has a long history that is transmitted through generations and generations through the telling of stories, proverbs and poetry, including through texts that are transmitted orally and when little bibliography can be found in the library, it is an important language for its speakers that needs further research and help in order to develop.

Each country possesses its own identity and language, we use as a final example a paragraph from a newspaper to analyse the grammatical structure and etymology of the Maltese sentence, and then to compare with Algerian:

"Il-UHM Voice of the Workers esprimiet l-inkwiet tal-haddiema li tirrappreżenta fil-Freeport ghad-deciżjoni tal-Prim Ministru lihu contra li lattività fil-Freeport tkompli tikber" [El UHM Voice of the Workers' expresses the restlessness the workers feel that represent the Freeport 
regarding the decision from the Prime Minister against the activity from Freeport, which is on the increase].

In this sentence, there is a syntactic and grammatical interface: the name of the group which is protesting is in English "Voice of the Workers", followed by the verb conjugated in Maltese, the article comes from Arabic but it has been adapted to Maltese conventions, followed by a noun from Latin, and an Arabic preposition "tal", the noun of which is borrowed from a variety of a North African type of Arabic "تع", but adapted to Maltese.

The word "haddiema" originates from Arabic equally adapted to Maltese phonetics, which is also the case of the conjunction "li" that comes from the Arabic word "الذي". The article "l" comes from the Arabic in the same way "Il)". The verb comes from Latin and the conjunction again follows Maltese conventional rules, the preposition "fil" is a fusion of the Arabic preposition “في" and the article "Jl)", followed by an English noun "Freeport", the verb that comes from Latin "tkompli" conjugated according to Maltese conventions and in the end the Arabic verb "tikber" [to grow] adapted to Maltese phonetics. It is a text found in a newspaper and for the Maltese people it is expressed in their native tongue, even if most of the words are foreign. The same occurred to Algerian, but as it is a language that is not recognized as such, it is considered as code-switching and it is not given due importance.

\section{Conclusion}

This study has allowed us to observe how the Maltese dialect has gone from being known as a "The language of the kitchen" to an official and national language. Once it was codified and adapted by influence of the Roman alphabet, research has developed which has permitted the creation of grammatical rules for its speakers.

This is what is in the pipeline for the Algerian language, although this would prove more of a challenge. Firstly, a political agreement would need to be established to be able to take objective decisions, and to regulate the native language of Algerian, as children start from the age of five at primary school, stumbling themselves upon a language distant from their own.

Arabisation was introduced into Algerian society after it became an independent state to establish an educational base which can look for a pure Arabic identity, after various years of colonization, but the reality of Arabisation does not reflect this.

Algeria has been a multicultural country since its creation, as the North-African region has been inhabited by the Berbers and Ottomans before the Arabs arrived, and the linguistic policies introduced by Algerian politicians have been part a linguistic planning process that required effort from both citizens and politicians as well. These policies required teachers 
and an administrative reform to reach their objectives, to create a standard Arabic, when the Berbers and the region of Cabilia needed to establish their native language officially. Present sociocultural factors in Algeria have influenced this linguistic planning, and amongst examples of this are: contact between different languages for centuries, the number of ethnicities that were present in the territory, religious influence, the impact of foreign meddling, and above all a generation clash: this was between parents that picked up a French education and children that received an Arabic one, and a society that finds itself in between the East and the West, between the adopted languages, the imposed languages and also the scientific and technological languages. The coexistence of different languages in the same society is a topic that politicians must strongly consider. A society that still has its administrative documents written in French, with Arabic translation, having a constitution whose values are based on Arabisation. For these reasons, more research is required within this field to force politicians into taking linguistic policies in Algeria seriously, and to recognize the identity of an Algerian.

It is necessary to create investigational groups to normalize grammatical rules for the Algerian language, with an immersive educational programme within the political and social system.

As we have mentioned before, the Maltese language has taken advantage of the cultural and linguistic richness present in the territory in order to normalize its official language. It is very important that Algerian studies its mother language, develops it and serve it as an incentive for Algerian literature to flourish, as it has not reach desired levels. A lot of poetry, stories and proverbs are transmitted from generation to generation orally, without having a recognised bibliography to encapsulate this abundant heritage and culture.

It is important that Arabic is taught and that it continues as an official language in Algeria, but Algerian also needs to have importance to affirm Algeria's identity.

It is very important to codify the language, most Algerians write in Latinate writing in Algerian, and this can be observed in social media frequently, as this is the present communication form of our time. This affirmation has been studied in a detailed fashion (Baya \& Kerras, p. 2016) to question the language used in Algeria through a sociolinguistic analysis via the social networking site Facebook. Due to the easiness of writing with keyboards, people opt to write with Latin letters, few people know how to write properly in Arabic by computer, but at a hand-written level the language is written equally with Arabic letters, and it is a topic that needs resolving through a general consent between politicians and researchers.

Algerian is the national language and it has potential to achieve official language status if the amount of research increases in this field, as 
there is a need to recognise its identity. Conservative politicians need to freshen up their methods to normalise the Algerian language and to recognise it as an official language alongside standard Arabic due to the need to confirm its own identity.

\section{References:}

1. Baya, M. L. \& Kerras, N. (2016). A sociolinguistic Study of the Algerian Language. Arab Worl English Journal, 3, 141-154.

2. Benrabah, M. (1999). Langue et Pouvoir en Algérie [Language and Power in Algeria]. Paris: Seguier.

3. Boubakour, S. (2008). Étudier le Français...Quelle Histoire! [Learning French...What a story!]. Réseau des Observatoires du Français Contemporain en Afrique, 23 (51-68).

4. Camilleri, A. (2016). Young Children Living Bilingually in Malta. Lingwistyka Stosowana, 17, 2 (1-13).

5. Guella, N. (2011). Emprunts Lexicaux dans les Dialectes Arabes Algériens [Loanwords in the Algerian Arabic Dialects]. Synergies Monde Arabe, 8 (81-88).

6. Hilbert, M. \& Krug, M. (2016). The Compilation of ICE Malta: State of the Art and Challenges along the Way. Germany: University of Bamberg.

7. Hoberman, R. \& Aronoff, M. (2003). The verbal morphology of Maltese: From Semitic to Romance. Language Processing and Acquisition in languages of Semitic, Root-Based. Morphology, 3, 6178.

8. Larzul, S. (2010). Grammatisation et Lexicographie de l'arabe algérien au XIX ${ }^{\mathrm{e}}$ siècle [Grammatisation and Lexicography of the Algerian Arabic in the XIX ${ }^{\mathrm{e}}$ Century]. Synergies Monde Arabe, 7 (89-100).

9. Martinet, A. (1980). Éléments de Linguistique Générale [Elements of General Linguistics]. Paris: Armand Colin.

10. Medane, H. \& Yahioui, KH. (2014). Le "français cassé" chez les jeunes Algériens: interference et calque au service de l'humour [The «broken French» within Algerian Youth: Interference and Calque in the Service of Humour]. Berlin: Congrès Mondial de Linguistique Française.

11. Merzouk, S. (2014). Le Français en Algérie, Création et Variation comme Vecteur d'Adaptation: le cas de l'Emprunt au Berbère [The French in Algeria, Creation and Variation as an Adaptation Vector : the Case of Borrowing into Berber]. Berlin: Congrès Mondial de Linguistique Française. 
12. Pascale, N. (2011). Maltese Dialects: the Effects of Globalization and Changing Attitudes on Malt's Linguistic Diversity. Omertaa: Journal of Applied Anthropology, 5 (526-539).

13. Sciriha, L. (2002). The Rise of Maltese in Malta: Social and Educational Perspectives. Intercultural Communication Studies XI, 3 (95-106). 